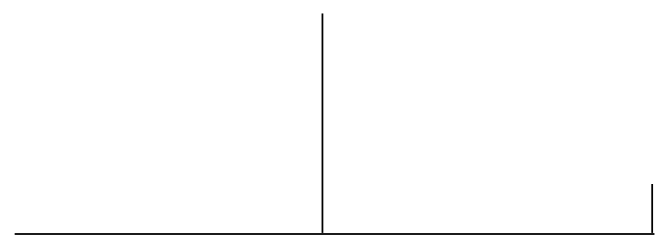

Rev. Latinoam. Psicopat. Fund., São Paulo, v. 13, n. 4, p. 635-647, dezembro 2010

\title{
profissional de referência em Saúde Mental: das responsabilizações ao sofrimento psíquico*
}

\author{
Elisa Alves Silva \\ lleno Izídio da Costa
}

\begin{abstract}
O objetivo é abordar as responsabilizações do profissional de referência relatadas como geradores de sofrimento psíquico: vínculo com usuário, organização do trabalho e suporte institucional. Trata- se de uma pesquisa-ação realizada em Centros de Atenção Psicossocial de Goiânia - GO. Participaram 22 profissionais de diferentes áreas em grupos operativos de reflexão, e os dados foram examinados pela análise de conteúdo. É destacada a importância da dimensão clínica e do suporte institucional.
\end{abstract}

Palavras-chave: Serviços de Saúde Mental, profissional de referência, sofrimento psíquico, reforma psiquiátrica

* O artigo é uma parte da investigação realizada durante o curso de Mestrado em Psicologia Clínica e Cultura (PsiCC) da Universidade de Brasília (UnB), intitulada "Dores dos cuida-dores em saúde mental: estudo exploratório das relações de (des)cuidado dos profissionais de saúde mental em Centros de Atenção Psicossocial de Goiânia-Go". Defendida e aprovada em março de 2007 na Universidade de Brasília (UnB) pela primeira autora sob orientação do segundo autor. 
Este artigo aborda questões concernentes a um dos dispositivos clínicos do arranjo organizacional do trabalho em saúde mental, designado como profissional de referência. ${ }^{1}$ A constituição desse dispositivo tem como finalidade o estreitamento do vínculo entre os profissionais e usuários, a proposta da interdisciplinarida

de e a interlocução com as redes familiares, sociais, culturais, socioeducacionais, entre outros. O propósito é um novo cuidado que será articulado pelo referente, garantindo a continuidade do tratamento com a inclusão dos aspectos subjetivo, social, familiar e laboral (Campos, 1999; Furtado \& Miranda, 2006).

A instalação das práticas desse novo cuidado atinge todos os serviços guiados por princípios do Movimento da Reforma Psiquiátrica Brasileira, que empregam uma transformação do modelo assistencial em saúde mental. Sendo assim, a Política Nacional de Saúde Mental tem como diretriz a implantação de serviços substitutivos e a redução gradual e planejada de leitos em hospitais psiquiátricos (Brasil, Ministério da Saúde, 2009). Nesse contexto, temos os Centros de Atenção Psicossocial (CAPs), que consistem em serviços comunitários e territorializados, funcionando diariamente com propostas de ações que priorizam as atividades grupais e a (re)inserção social dos usuários com sofrimento psíquico.

No Manual dos CAPS, elaborado pelo Ministério da Saúde (2004), o técnico de referência é definido como aquele que tem como responsabilidade o monitoramento do usuário, o projeto terapêutico individual, o contato com a família e a avaliação das metas traçadas no projeto. Furtado e Miranda (2006) acrescentam que o dispositivo técnico de referência constitui uma aproximação entre o profissional ou equipe a certo número de usuários, ocasionando uma assistência de modo singular por meio de um projeto terapêutico individual.

Entretanto, em pesquisas recentes, essas atribuições se estendem, dando espaço às demandas burocráticas, assistenciais e organizacionais,

1. Na literatura, podemos encontrar várias designações ao profissional de referência: "profissional referente", "técnico de referência", "equipe referente". No presente artigo utilizamos essas terminologias como sinônimas a fim de resguardar todas as atribuições imbuídas no desempenho dessa atividade.

Rev. Latinoam. Psicopat. Fund., São Paulo, v. 13, n. 4, p. 635-647, dezembro 2010 
que fogem ao escopo da clínica e, frequentemente, são distantes do exercício profissional que a função exige. Os estudos revelam que esse dispositivo trouxe novas responsabilizações, bem como novas reconfigurações das relações: profissional referente-usuário-equipe-família-sociedade, no campo da saúde mental (Campos, 1999; Furtado \& Miranda, 2006; Miranda \& Onocko Campos, 2008; Onocko Campos et al., 2009; Silva, M., 2005; Silva, E., 2007). Assim, o dispositivo profissional referente, instituído para atender as atuais práxis e aos princípios éticos da Reforma Psiquiátrica, implica em mudanças no modo de trabalho desenvolvido pelos profissionais, reinventando a maneira de ser e de agir dos trabalhadores no cuidado com o outro.

Nossa experiência junto aos serviços de saúde mental nos possibilitou identificar diversos questionamentos na atuação do papel de técnico de referência. $\mathrm{O}$ intuito desse estudo é elucidar as dificuldades apresentadas que limitam a prática no cotidiano de trabalho e os fatores que desencadeiam o sofrimento psíquico ocasionando impactos que atingem a realidade psíquica desses profissionais.

\section{Metodologia}

Os dados foram obtidos por meio da formação de três grupos com representantes de diferentes categorias profissionais de nível superior - Arteterapia, Artes Plásticas, Serviço Social, Enfermagem, Musicoterapia, Educação Física, Psicologia e Psiquiatria. Os três grupos formados totalizaram 22 profissionais que tiveram números diferenciados de encontros, que variaram de sete a nove.

Trata-se de uma pesquisa com abordagem qualitativa, com base na pesquisa-ação. Por seu duplo objetivo de modificar a realidade e produzir conhecimentos favoreceu que os participantes e pesquisadores se envolvessem de modo cooperativo e participativo, levando a novas reflexões e práticas (Barbier, 2002; Thiollent, 1996).

Os grupos operativos de reflexão foram a estratégia escolhida para a realização da pesquisa-ação. As técnicas utilizadas foram selecionadas em comum acordo entre os participantes e pesquisadores, sendo: leituras de textos seguidas de discussões da temática abordada; técnicas e vivências grupais que possibilitassem a reflexão em torno da atuação profissional e institucional; questionários e avaliações dos encontros.

Os dados foram analisados pelo método de Análise de Conteúdo de Bardin (1977), que propõe evidenciar opiniões, críticas, julgamentos, reações afetivas nos relatos e vivências que os participantes tiveram nos encontros. Nesse sentido, Franco (2003) esclarece que as informações colhidas precisam ser acompanha- 
das pelo contexto e experiências em que foram elaboradas e construídas, sendo a mensagem a expressão de um significado e sentido.

O processo de organização da análise de conteúdo envolveu a pré-análise, no qual se fez a escolha do material coletado e a leitura flutuante, ou seja, os registros transcritos dos encontros com os grupos. Em seguida produziram-se as categorias com temas que possuem a mesma significação (Bardin, 1977; Franco, 2003).

Após transcrição e análise dos dados, foi marcado um encontro com cada grupo participante da investigação, visando validação e contestação dos resultados encontrados. A pesquisa foi submetida e aprovada pelo Comitê de Ética em Pesquisa da Pontifícia Universidade Católica de Goiás.

\section{Análise e discussão dos resultados}

Nos resultados com a temática do profissional referente, três categorias relacionadas ao sofrimento psíquico foram evidenciadas: 1) vínculo com usuário e o sofrimento psíquico do referente; 2) organização do trabalho e o papel do referente e 3 ) suporte institucional e a dimensão clínica no trabalho do profissional de referência.

\section{O vínculo com usuário e o sofrimento psíquico do referente}

No campo da saúde mental, a relação entre profissional e usuário é uma das ferramentas-chave de intervenções no trabalho, considerada primordial no desenvolvimento do processo terapêutico. Logo, a relação profissional-usuário passa a ser agente de mobilizações no âmbito da realidade psíquica, bem como no desenvolvimento do trabalho (Fraga, 1997; Silva, E., 2007).

Nesse contexto, o profissional de referência é um dispositivo que potencializa alterações na realidade psíquica dos profissionais de saúde, por valorizar a construção do vínculo com o usuário como instrumento essencial do trabalho. A relação que envolve o profissional de referência com usuário tem aparecido nas recentes pesquisas como provocadora de vários sentimentos que revelam o sofrimento psíquico: angústias, impotências, preocupações e responsabilizações (Furtado \& Miranda, 2006; Miranda \& Onocko Campos, 2008; Onocko Campos et al., 2009; Silva, E., 2007). Quando referido especificamente à atuação do profissional no papel de referente, para a maioria dos participantes da pesquisa, es- 


\section{SAÚDE MENTAL}

sas responsabilizações e preocupações aumentam, ocasionando também o acréscimo das angústias:

"Aqui no CAPs a gente fica mais em contato com o sofrimento, tanto da pessoa, como da família, ainda mais quando é referente, você tem contato com o dia-a-dia, sabe mais desse dia-a-dia. Então fica parecendo que o paciente vira propriedade, tudo que acontece tá na sua responsabilidade e isso pesa, a gente sofre, porque é muita responsabilidade com poucos momentos para compartilhar" (Enfermeira).

Os participantes relataram que, quando referentes, se sentem responsáveis pelos usuários que estão sob seus cuidados. Essa maior responsabilidade deve-se ao fato de que o profissional se vê diante da centralização do poder pela tomada de decisões, pois o acompanhamento do projeto terapêutico e dos objetivos traçados fazem parte de suas tarefas. Os relatos demonstram que essas experiências colocam o profissional diante de seus conflitos e inseguranças:

"Eu tô aqui me lembrando de um caso que era uma das adolescentes que eu era referente e eu tava ficando com uma função doentia com ela, porque eu saia daqui pensando o que ela ia fazer naquele final de semana, eu me sentia responsável pelas ações que ela podia ter, comecei até a sonhar com ela. Nossa, foi um caso tão sofrido pra mim, eu me cansava tanto, ela teve muitas recaídas porque usava drogas, eu sentia que estava fracassando, tive que dar um tempo desse caso" (Musicoterapeuta).

Esse novo cuidado no campo da saúde mental requer uma maior disponibilidade por parte do profissional, principalmente quando se é o profissional de referência. Essa atitude de disponibilidade geralmente vai além das competências técnicas para o exercício das funções que são exigidas. Esse acúmulo de exigências pode gerar tensões, adoecimentos e desequilíbrio psíquico (Silva, E., 2007).

Em alguns relatos observamos o uso de defesas psíquicas pelos profissionais, que tentam amenizar a percepção da realidade: alguns negam relatar os aspectos difíceis na atuação do papel referente. Esses profissionais se mostraram distanciados das atividades práticas, revelando um discurso politizado e ao mesmo tempo incoerente com as ações que se propunham a desempenhar:

"Nossa gente, dentro do nosso trabalho, a gente tem que pensar mais no outro. Aqui é nosso trabalho, temos que nos engajar nas nossas responsabilizações mesmo com o outro. Quem precisar de cuidado ou de apoio tem que procurar isso fora... os meus sofrimentos nunca me pareciam causas do meu trabalho, hoje eu 
sinto uma frustração com relação ao trabalho, mas ainda não me parece que eu precise de cuidados pra pedir cuidados de profissional. A gente trabalha com políticas públicas, o que as pessoas estão procurando a gente não tem muito o que fazer, não tem! É, talvez seja a dificuldade em querer fazer tudo e não ter o que fazer, não ter como cuidar, isso talvez seja sofrido" (Assistente Social).

Percebemos que essas soluções, em sua maioria, são feitas por via do recalque. Martins (2005) esclarece que recalque ou defesa são "qualquer operação psíquica inconsciente que leve o sujeito a não se implicar no que possa sentir, pensar, querer e agir no ato mesmo de experimentar essas atividades psicológicas" (p. 178).

Na pesquisa de Miranda (2009) com grupos focais de trabalhadores nos CAPs de Campinas, observou-se que o sofrimento relatado pode levar a equipe a estruturações inconscientes de defesas psíquicas. No profissional referente foi notada a defesa de identificação narcísica com o paciente, produzindo a sensação de onipotência no profissional, no sentido de conseguir e sentir que precisa oferecer respostas a todas as demandas trazidas pelo usuário. Nesse sentido, a autora destaca que apenas um adoecimento físico é capaz de interromper as práticas de tudo fazer e tudo saber, revelando com isso a intensidade que envolve tais defesas.

Vários autores esclarecem que a utilização das estratégias defensivas tem o seu papel positivo, pelo fato de mitigar aspectos conflituosos e dolorosos de algumas experiências do trabalho. Entretanto, é preciso observar como são utilizadas essas estratégias, pois a sensação de uma estabilidade psíquica artificial mascara um sofrimento psíquico mais intenso (inconsciente), o que pode adquirir uma dimensão patológica que acaba por interferir no cotidiano do trabalho, estendendo-se à vida social (Dejours \& Abdoucheli, 2009; Mendes \& Morrone, 2002).

\section{Organização do trabalho e o papel de referente}

Martins (2005) aponta as quatro dimensões pathicas que são indicadoras da vida pulsional: gozar, amar, trabalhar e comunicar. Para o autor, o chamado adoecimento psíquico será sempre a expressão do comprometimento de uma dessas atividades. Com relação ao trabalho, ressalta que é preciso levar em consideração todo o contexto no qual esse sofrimento se manifesta e a relação de vários aspectos, como, por exemplo, a organização do trabalho que tem sido objeto de pesquisas nos anos mais recentes.

Rev. Latinoam. Psicopat. Fund., São Paulo, v. 13, n. 4, p. 635-647, dezembro 2010 
A organização do trabalho compreende os aspectos que envolvem as relações que são estabelecidas no ambiente laboral, as condições físicas e materiais, e a divisão de tarefas. Logo, as vivências de prazer ou sofrimento estão relacionadas à interação entre esses aspectos (Dejours, 1987).

No campo da saúde mental, as práticas do profissional referente são direcionadas a um regulamento e gerenciamento de um conjunto de recursos e encargo pelo cuidado. É uma estratégia de gestão, para reorganizar o serviço em equipe, que faz com que o profissional se implique mais ao projeto reformista e, consequentemente, eleva a responsabilidade na organização trabalho (Silva, M., 2007). Contudo, essa estratégia de organização do trabalho traz demandas que não conseguem ser supridas pelo próprio sistema de saúde.

"No CAPs tem a vantagem de ter mais contato com o paciente e poder ajudar mais, mas também de ficar mais impotente, porque a família tem que aderir e a pessoa precisa estar aqui no grupo duas vezes por semana, aí a família não tem como ter passe pra todo mundo. Aí precisa de medicação, a medicação tá em falta, a pessoa não sabe o que vai almoçar, como é que vai comprar o remédio. É um punhado de coisas que angustia a gente e também preocupa" (Psiquiatra).

Os profissionais explicaram que se sentem desmotivados quando se deparam com as condições físicas e materiais no cotidiano de trabalho e com a problemática rede social na qual estão inseridos os usuários. Lidar com a precariedade do sistema de saúde e da rede social do usuário intensifica os sentimentos de desânimo, cansaço, ansiedade, frustração, tensão emocional, sobrecarga e estresse no trabalho.

Esse novo arranjo organizacional, no qual é estimulado um maior vínculo entre o profissional de saúde e o usuário, provoca maiores responsabilizações e engajamento por parte dos trabalhadores. Surgem, assim, os dilemas hoje instaurados no cotidiano desses profissionais, que norteiam também as responsabilizações por equipamentos sociais que não estão ligados somente à área da saúde.

"O grande problema às vezes é a rede de atendimento que a gente tem, porque a minha atuação como Assistente Social não está centrada no ambiente institucional. As demais políticas intersetoriais também estão precarizadas como na saúde, a gente não consegue fazer os encaminhamentos e quando se consegue eu já faço desacreditada do resultado daquilo, infelizmente eu conheço, é muito cansativo isso" (Assistente Social). 
Algumas tarefas ultrapassam o sistema de saúde, demonstrando outros campos precários (familiar, social, cultural, econômico). O profissional encontra impasses que limitam as ações necessárias e, na maioria dos casos, o faz sentir-se sobrecarregado, impotente e descrente; tornando-o vulnerável ao adoecimento. Os exemplos relatados são diversos: falta de medicação, moradia em condições mínimas de sobrevivência, carência no suporte familiar, ausência de alimentação adequada, dentre outros.

Nesse sentido, Migott (2001) afirma que o conflito gerado pela lacuna entre o desejo do profissional e a realidade do trabalho ocorre quando a relação entre o trabalhador e a organização do trabalho não são compatíveis. Nesses momentos aparece o bloqueio, o cansaço, a frustração, as dificuldades das relações interpessoais, a desesperança; enfim, sentimentos que levam ao sofrimento e à tensão pessoal e profissional.

\section{O suporte institucional e a dimensão clínica no trabalho do profissional referente}

A dimensão clínica é outra característica que se insere nas atividades do referente, sendo que nessa atuação há maior proximidade no vínculo que ocorre entre o profissional e o usuário, implicando processos advindos do relacionamento terapêutico. Esse envolvimento ocasiona mais responsabilizações que remetem a aspectos emocionais que são sentidos pelos profissionais de referência como encargo em ter que solucionar todas as dificuldades do usuário.

Observamos que a prática do profissional referente nos CAPs pesquisados suscita confusões e distorções entre os trabalhadores e as equipes. Por conseguinte, há ainda dúvidas no agir e nos sentimentos envolvidos na vinculação que se estabelece entre o profissional referente e o usuário.

"Chegou num momento que eu comecei a dizer para! Eu tenho que parar com isso, o sofrimento é da pessoa, eu não posso ficar trazendo pra mim responsabilidade pelo sofrimento da pessoa. No momento que eu tô com a pessoa eu tento contribuir, mas eu sofro porque ela tá sofrendo. Poxa sabe, ele sofre tanto com essa religiosidade dele, aí penso: nossa, eu tenho que dar um jeito de diminuir isso. Eu até tenho melhorado em não querer me envolver tanto, mas ainda tem me incomodado muito" (Educador Físico).

Em pesquisa realizada por Silva, M. (2007), nos CAPs da cidade do Rio de Janeiro, foi notado que existem incertezas na definição do papel de referente e que 
os trabalhadores ainda não sabem ao certo quais são as funções e responsabilidades de quem está exercendo a referência ou até mesmo quem pode exercê-la. A garantia é que, quando se alude a essa atuação, o responsabilizar-se é visto de um modo mais intenso e diferenciado.

Dessa maneira, as pesquisas que abordam essa temática indicam que ainda há poucos estudos científicos relativos à dimensão clínica do profissional de referência e recomendam a necessidade de criar e propiciar momentos para discutir e avaliar o dispositivo profissional de referência (Miranda, 2009; Miranda e Onocko Campos, 2008; Silva, E., 2007). Essa referência feita ao usuário nem sempre é clara, há ainda uma confusão “... se o que se pretende estreitar são as relações entre serviço e população, profissional e usuário, funcionário e organização ou todos eles" (Silva, M., 2007, p. 23).

Ressalta-se também que o caráter terapêutico desse dispositivo requer mais discussões teóricas e clínicas, pois envolve complexidades subjetivas e ações advindas do campo clínico. É necessário pensar na clínica desenvolvida por esse profissional para além das questões burocráticas que a atuação exige. Afinal, há um componente essencialmente clínico, que é a relação estabelecida no vínculo entre profissional de referência e o usuário.

As questões relacionadas à sobrecarga na atuação do papel referente são minimizadas quando ocorrem as reuniões técnicas ou reuniões da miniequipe, na qual há possibilidade de trocas e compartilhamento das decisões a encaminhamentos do trabalho. Essas reuniões fazem parte da divisão de tarefas e são consideradas imprescindíveis para o exercício da interdisciplinaridade. Porém, alguns profissionais afirmaram que essas reuniões são difíceis de acontecer no sentido da proposta interdisciplinar, havendo um emaranhamento em tarefas meramente técnicas e burocráticas.

Os profissionais dessa pesquisa, quando questionados sobre quais mecanismos os auxiliariam nas reflexões e práticas em torno das atividades do CAPs, foram unânimes em dizer que a supervisão clínico-institucional é um instrumento que oferece suporte tanto ao trabalho como a aspectos emocionais próprios ao contato intersubjetivo. A dificuldade está no fato dessas supervisões serem espaços que possuem caráter transitório nas ações direcionadas ao CAPs. Evidenciamos a necessidade da supervisão clínico-institucional como instrumento de suporte para o desenvolvimento do trabalho.

\section{Considerações finais}

As pesquisas e experiências demonstram que o profissional de referência constitui um importante dispositivo do arranjo organizacional da saúde mental. Para 
Furtado (2007), esse dispositivo trouxe uma qualificação na atenção ao usuário, como também possibilitou a interação técnica e subjetiva entre as equipes dos serviços de saúde, deslocando o poder das especialidades profissionais e reforçando o poder de gestão da equipe interdisciplinar.

No entanto, a atuação de referência exige uma articulação de vários saberes e de diversos campos relacionais (familiar, laboral, social, cultural etc.). Essa construção acontece em um terreno fértil de múltiplas possibilidades de trocas e conflitos. Por isso, o modelo de gestão e a organização do serviço precisam garantir espaços sistemáticos de reuniões ou encontros que estabeleçam planejamento, discussões de caso, supervisão clínico-institucional, capacitação, enfim, espaços que considerem a complexidade e a intensidade das relações que pressupõem o campo da saúde mental.

Enfatizamos também o fundamental papel das ações de Políticas Públicas voltadas à saúde do trabalhador, na garantia de regulamentar e implementar os projetos destinados aos profissionais da saúde mental, tendo o caráter de continuidade e efetividade dessas propostas. Acreditamos que mais avaliações e acompanhamentos dessas experiências garantem o aperfeiçoamento dos serviços, reformulando ações que envolvem todos os atores sociais inseridos no campo da Saúde Mental.

\section{Referências}

BArbier, R. A pesquisa-ação. Brasília: Plano Editora, 2002.

Bardin, L. Análise de conteúdo. Lisboa: Persona Edições, 1977.

Brasil. Ministério da Saúde. Secretaria de Atenção à Saúde. Departamento de Atenção Básica. Diretrizes do NASF (Núcleo de Apoio à Saúde da Família). Ministério da Saúde, Secretaria de Atenção à Saúde, Departamento de Atenção Básica. Brasília: Ministério da Saúde, 2009.

CAmpos, G. W. S. Equipes de referência e apoio especializado matricial: um ensaio sobre a reorganização do trabalho em saúde. Revista Ciência \& Saúde Coletiva, Rio de Janeiro, v. 4, n. 2, p. 393-403, 1999.

Dejours, C. A loucura do trabalho: estudo de psicopatologia do trabalho. 2. ed. São Paulo: Cortez /Oboré, 1987.

Dejours, C.; Abdoucheli, E. Itinerário teórico em psicopatologia do trabalho. In: Dejours, C. et al. (Org.). Psicodinâmica do trabalho: contribuições da escola dejouriana à análise da relação prazer, sofrimento e trabalho. São Paulo: Atlas, 2009. p. 119-143. 


\section{SAÚDE MENTAL}

Fraga, A. P. V. Repercussões subjetivas do atendimento a psicóticos em profissionais de saúde mental. 1997. 136p. Dissertação (Mestrado em Psicologia Clínica). Universidade de Brasília - UnB.

Franco, M. L. P. B. Análise de conteúdo. Brasília: Plano Editora, 2003.

FuRTADO, J. P. Equipes de referência: arranjo institucional para potencializar a colaboração entre disciplinas e profissões. Revista Interface, v. 11, n. 22, p. 239-255, mai/ ago. 2007.

Furtado, J. P.; Miranda, L. O dispositivo "técnicos de referência" nos equipamentos substitutivos em saúde mental e o uso da psicanálise winnicottiana. Revista Latinoamericana de Psicopatologia Fundamental, São Paulo, ano IX, n. 3, p. 508-524, set. 2006.

Martins, F. Psicopathologia I: prolegômenos. Belo Horizonte: PUC Minas, 2005.

Mendes, A. M.; Morrone, C. F. Vivências de prazer-sofrimento e saúde psíquica no trabalho: trajetória conceitual e empírica. In: Mendes, A. M. et al. (Org.). Trabalho em transição, saúde em risco. Brasília: Ed. Universidade de Brasília, 2002. p. 42-57.

Migott, A. M. B. Cuidado construtivo: desvelando questões existenciais entre o agir ético e o técnico. Série Enfermagem 4. Passo Fundo: UPF, 2001.

MinistéRio da SAúde. Secretaria de Atenção à Saúde. Departamento de Ações Programáticas Estratégicas. Saúde mental no SUS: os centros de atenção psicossocial. Brasília: Ministério da Saúde, 2004.

Miranda, L. Transitando entre o coletivo e o individual: reflexões sobre o trabalho de referência junto a pacientes psicóticos. 2009. 301p. Tese (Doutorado em Ciências Médicas), Universidade Estadual de Campinas - Unicamp.

Miranda, L.; Onocko, C., Rosana, T. Análise do trabalho de referência em Centros de Atenção Psicossocial. Revista Saúde Pública, São Paulo, v. 42, n. 5, p. 907-913, 2008.

Onocko, C.; Rosana, T. et al. Avaliação da rede de centros de atenção psicossocial: entre a saúde coletiva e a saúde mental. Revista Saúde Pública, São Paulo, v. 43, suppl. 1, p. 16-22, 2009.

Silva, E. A. Dores dos cuida-dores em saúde mental: estudo exploratório das relações de (des)cuidado dos profissionais de saúde mental em Centros de Atenção Psicossocial de Goiânia - GO. 2007. 165p. Dissertação (Mestrado em Psicologia Clínica e Cultura), Universidade de Brasília - UnB.

Silva, M. B. B. Atenção psicossocial e gestão de populações: sobre os discursos e as práticas em torno da responsabilidade no campo da saúde mental. PHYSIS: Revista Saúde Coletiva, Rio de Janeiro, v. 15. n. 1, p. 127-150, 2005.

. O técnico de referência no Centro de Atenção Psicossocial: uma nova especialidade no campo da saúde mental? Revista Vivências, Natal, n. 32, p. 227-223, 2007. 


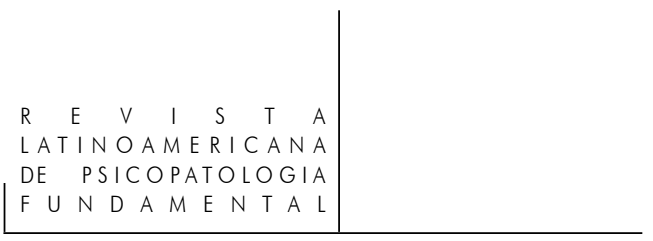

Thiollent, M. Metodologia da pesquisa-ação. 7. ed. São Paulo: Cortez, 1996.

\section{Resumos}

(The reference professional in mental health: from accountabilities to mental suffering)

The objective of this article is to address the accountabilities of reference professionals reported as generators of mental suffering, including relationships with users, organization of work and institutional support. This is an action research carried out at Psychosocial Care Centers in Goiânia, Go, Brazil. Twenty-two professionals from different areas working in operative groups of reflection, together with related data, were analyzed through content analysis. The importance of the clinical dimension and institutional support are stressed.

Key words: Mental health services, reference professionals, mental suffering, psychiatric reform

(Le professionnel de référence en Santé Mentale: des responsabilités aux souffrances psychiques)

L'objectif est de traiter des responsabilités du professionnel de référence, décrites comme étant génératrices de la souffrance psychique: le rapport avec l'usager, l'organisation du travail et l'appui institutionnel. Il s'agit d'une recherche-action menée dans des Centres de Soins Psychosociaux de Goiânia, état de Goiás. Vingt-deux professionnels de différents domaines ont participé à de groupes opérationnels de réflexion et les données ont été examinées à partir de l'analyse de contenu. L'importance de la dimension clinique et de l'appui institutionnel sont mises en relief.

Mots clés: Services de Santé Mentale, professionnel de référence, souffrance psychique, réforme psychiatrique

(El profesional de referencia en Salud Mental: de las responsabilizaciones al sufrimiento psíquico)

El objetivo es abordar a las responsabilizaciones del profesional de referencia relatadas como generadoras del sufrimiento psíquico: vínculo con el usuario, organización del trabajo y soporte institucional. Se trata de una investigación/acción llevada a cabo en Centros de Atención Psicosocial de Goiânia-GO. Participaron 22 profesionales de distintas áreas en grupos operacionales de reflexión y los datos han sido examinados por análisis del contenido. Es destacada la importancia de la dimensión clínica y del soporte institucional.

Palabras clave: Servicios de Salud Mental, profesionales de la referencia, sufrimiento psiquico, reforma psiquiátrica 
Citação/Citation: SiLva, E.A.; CostA, I.I. DA. O profissional de referência em Saúde Mental: das responsabilizações ao sofrimento psíquico. Revista Latinoamericana de Psicopatologia Fundamental, São Paulo, v. 13, n. 4, p. 635-647, dez. 2010.

Editor do artigo/Editor: Profa. Dra. Ana Cristina Figueiredo

Recebido/Received: 10.7.2010/ 7.10.2010 Aceito/Accepted: 10.7.2010/7.10.2010

Copyright: () 2009 Associação Universitária de Pesquisa em Psicopatologia Fundamental/ University Association for Research in Fundamental Psychopathology. Este é um artigo de livre acesso, que permite uso irrestrito, distribuição e reprodução em qualquer meio, desde que o autor e a fonte sejam citados/This is an open-access article, which permits unrestricted use, distribution, and reproduction in any medium, provided the original author and source are credited.

Financiamento/Funding: Os autores declaram não ter sido financiados ou apoiados/The authors have no support or funding to report.

Conflito de interesses/Conflict of interest: Os autores declaram que não há conflito de interesses/The authors declare that has no conflict of interest.

\section{Elisa Alves Silva}

Doutoranda em Psicologia Clínica e Cultura pela Universidade de Brasília - UnB (Brasília, DF, Brasil); mestre em Psicologia Clínica e Cultura pela mesma universidade; psicóloga; membro do Grupo de Intervenção Precoce nas Psicoses - GIPSI (Brasília, DF, Brasil); membro fundador da Associação de Saúde Mental do Cerrado - ASCER (Brasília, DF, Brasil).

Rua Barão do Rio Branco, Qd. 37, Lt. 06/07, Casa 04 - Parque Anhanguera. 74340-040 Goiânia, GO, Brasil

e-mail: elisapsi@gmail.com

\section{ILENo Izídio dA CosTA}

Doutor em Psicologia Clínica pela Universidade de Brasília - UnB/Warwick University (Brasília, DF, Brasil/Coventry, Inglaterra); professor adjunto do Departamento de Psicologia Clínica da Universidade de Brasília - UnB; MA em Filosofia e Ética da Saúde Mental pela Warwick University (Coventry, Inglaterra); coordenador do Grupo de Intervenção Precoce nas Psicoses - GIPSI (Brasília, DF, Brasil); Presidente da Associação de Saúde Mental do Cerrado - ASCER (Brasília, DF, Brasil).

ICC Sul, Campus Universitário Darcy Ribeiro

70910-900 Brasília, DF, Brasil

e-mail: ileno@unb.br 